Journal of Universal Computer Science, vol. 18, no. 1 (2012), 123-141

submitted: 15/7/11, accepted: 9/12/11, appeared: 1/1/12 @ J.UCS

\title{
OER Development and Promotion. Outcomes of an International Research Project on the OpenCourseWare Model
}

\author{
Edmundo Tovar \\ (Universidad Politécnica de Madrid, Madrid, Spain \\ etovar@fi.upm.es) \\ Nelson Piedra, Janneth Chicaiza, Jorge López \\ (Universidad Técnica Particular de Loja, Loja, Ecuador \\ nopiedra@utpl.edu.ec, jachicaiza@utpl.edu.ec, jalopez@utpl.edu.ec) \\ Oscar Martinez-Bonastre \\ (Miguel Hernandez University, Elche, Spain \\ oscar.martinez@umh.es)
}

\begin{abstract}
In this paper, we describe the successful results of an international research project focused on the use of Web technology in the educational context. The article explains how this international project, funded by public organizations and developed over the last two academic years, focuses on the area of open educational resources (OER) and particularly the educational content of the OpenCourseWare (OCW) model. This initiative has been developed by a research group composed of researchers from three countries. The project was enabled by the Universidad Politécnica de Madrid OCW Office's leadership of the Consortium of Latin American Universities and the distance education know-how of the Universidad Técnica Particular de Loja (UTPL, Ecuador). We give a full account of the project, methodology, main outcomes and validation. The project results have further consolidated the group, and increased the maturity of group members and networking with other groups in the area. The group is now participating in other research projects that continue the lines developed here.
\end{abstract}

Keywords: OCW, OpenCourseWare, OER, Open Educational Resources, Semantic Web, Linked Data, Social Networks Analysis, SNA

Categories: L.6.0, L.3.2, L.3.0, L.1.4, L.1.2

\section{Introduction}

Higher education institutions have for years promoted numerous procedures to improve the visibility of their educational and research activities. On this ground, they have been using alternative methods, like new technologies, e.g., the Internet, collaborative web-based platforms, e-learning environments, etc., to disseminate such activities beyond their own campuses.

In this paper, we describe the successful results of an international research project focused on the use of Web technology in the educational context. The article explains this international project, funded by public organizations and developed over the last two academic years. It focuses on the area of open educational resources 
(OER) and particularly on educational content for the OpenCourseWare (OCW) model. The project goals were inspired by emergent research lines within the OCW movement today, like the promotion of standards to enhance educational content visibility and usability, the development of the OER production cycle and the promotion of OER interoperability and reusability using Semantic Web research, without losing sight of the OER quality improvement issue.

The paper is structured as follows. The next section introduces the research team background and describesthe selected technologies for this project. We then give a full account of the project, methodology, main outcomes and validation. To conclude the article, we describe how the successful results portend optimistically for the future.

\section{Background}

\subsection{GICAC's evolution}

The researchers who participated in the project described in this paper are members of the Higher Education Institution Quality Management Innovation Group, GICAC. GICAC was approved as a consolidated group by the UPM in June 2006. These researchers began to cooperate in 2006 as part of a joint international PhD programme between Universidad Politécnica de Madrid (UPM, Spain), Universidad Técnica Particular de Loja (UTPL, Ecuador) and Universidad Católica del Norte (UCN, Chile). They are members of the UPM, UTPL and the Universidad Mayor San Andrés (UMSA, Bolivia).

The main initial goal of the collaboration among these higher education institutions was $\mathrm{PhD}$ researcher training focused on advanced software, intelligent system and distributed environment development technologies, in a particular with a group of hard-working young researchers at UTPL. Teething troubles were topped by the large geographical distance between the three institutions or the complexity of scheduling transatlantic travel that disrupted researcher agendas.

On this ground, the first group of participants promoted the development of a technological framework that would strengthen research collaboration between research teams located in different countries and different time zones [Tovar, 2008]. This project was developed as part of the UPM Relations with Latin America Programme. Specifically, we developed a web portal that embraced different technologies and provided contents in this technological framework.

The technologies selected for this project supported individual and even collaborative access to literature and Internet links shared by the research team. Additionally, they supported synchronous communication among researchers located in different geographical areas. The main outcome was a virtual learning environment with public and private repositories of scientific papers, research material, collaborative multimedia contents and forums for asynchronous and real-time meetings and exchange of contents, among other possibilities (see Figure 1). 


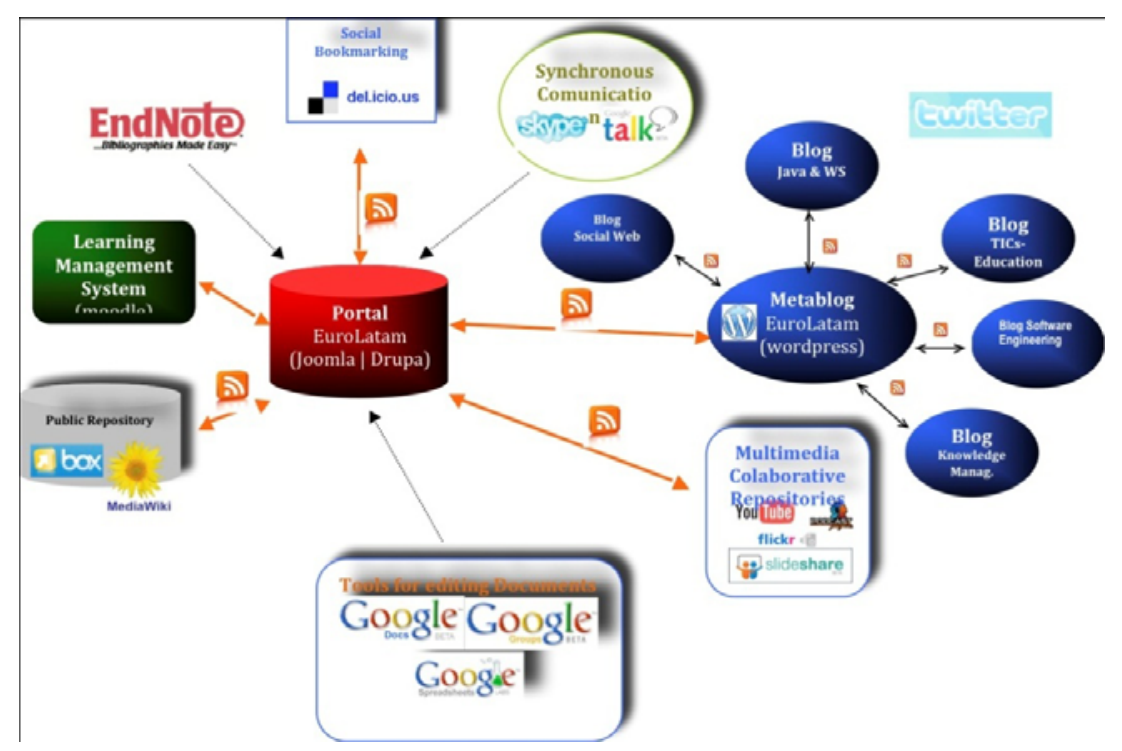

Figure 1: Technological Framework for Engineering UPM and UTPL Academic and Research Networks

This setup led to the establishment and management of several research lines by organizing PhD course resources. Also, it included a set of Web 2.0 technologies that were applied to the development of other training programmes, e.g., EHEA-compliant master's degrees. Consequently, this framework was the factor that had the biggest impact on the later development of joint international projects started up by this group of researchers.

Section 2.2 details the research in which this collaborative environment has been successfully used.

\subsection{State of the Art. Research Lines}

The web technologies applied to education research area has been the core of the research team's work over recent years. This section introduces the state of the art of the selected technologies used in this international project, as well as concepts necessary to understand the scope of the work presented here.

\subsubsection{Open Educational Resources}

Educational and scientific contents are the jewel in the crown of today's knowledgebased society. However, they are sometimes not easy to retrieve due to access control, licences, technical requirements, etc. For that reason, initiatives dealing with open access have been promoted in recent years. [Ziliotto, 2008] outlines the problem sand trends related to this initiative. Open educational practices and resources (OER) are a 
direct response to the privatization of knowledge, i.e., they promote global exchange with the aim of increasing human intellectual capacity. Thus, organizations and people increasingly share their digital learning practices and resources through the web in a free and open spirit [OLCOS, 2007]. The term OER was originally coined in 2002 at a UNESCO Forum on OpenCourseware (OCW). OER are educational resources that are freely available for use by educators, students and autodidacts that do not have pay royalties or licencefees. The main purpose of OERs then is to provide Internet-based educational resources for consultation, use and adaptation free of charge and for non-commercial purposes. Secondly, OERs have legal [Fitzgerald, 2007] and economic [Casserly, 2007] connotations. Since its creation, open access to educational and scientific content has been gaining support all over the world and has become a topic of interest for many higher education institutions. Emerging technologies such as the Social Web [O’Reilly, 2005], Semantic Web [Berners-Lee, 2001] and Linked Data [Berners-Lee, 2006] have a lot of potential in this area for OER and OCW creation, distribution and discovery. From the viewpoint of teachers and learners, the main contributions of OERs are full access, reusability and educational content sharing, etc., Figure 2 below illustrates other interesting advantages for this community of users.

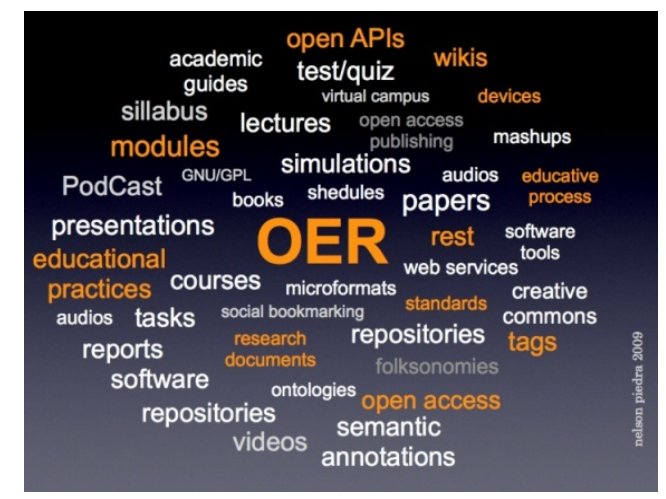

Figure 2: Open Educational Resources Concept Mind Map

Open licences have enabled OER re-use and global exchange. Social authoring offers great flexibility for distributing educational contents across the web. Some of the main advantages of OER are free use, distribution and access to their content. There are options, like Creative Commons, permitting everything from the free distribution of copies to OER adaptation and remixing. This is subject to some OER factors, like Attribution, NonCommercial, No Derivate Works, ShareAlike conditions, etc. In the context of the project presented in this paper, Creative Commons worked with UTPL in 2008 to create Creative Commons (CC) licences 3.0 and other specific legal tools for Ecuadorian jurisdiction. CC enabled the creator of a work to establish open and restrictive rights that make it possible to legally share, reuse, use commercially or establish any sort of combination. 


\subsubsection{OpenCourseWare}

One of the most important examples of the global promotion of OER is the OpenCourseWare (OCW) initiative. OCW focuses on the development and free distribution of courses and high-quality higher education materials. Much of the progress of OCW is derived from the work of the OpenCourseWare Consortium (OCWC) and Universia.net.

OCW-based materials are organized as courses and often include course planning materials and assessment tools, as well as thematic content. Secondly, OCW contents are free and openly licensed, accessible to anyone, anytime via Internet.

On the other hand, OCWC is a worldwide community of hundreds of universities and associated organizations committed to advancing OCW and its impact on global education. OCWC serves as a resource for starting and sustaining OCW projects, as a coordinating body for the movement on a global scale and as a forum for the exchange of ideas and future planning.

\subsubsection{Social Software}

International interest in OER is growing [OECD, 2007].Organizations likeUNESCO, OECD, World Bank, European Lifelong Learning Programme, Commonwealth of Learning (COL), William and Flora Hewlett Foundation and the Soros Foundations Network are providing funds, practices and content to support the OER movement [Downes, 2007].

Social software [O’Reilly, 2005] focuses on content, relationships and knowledge and technology illiteracy. [Richardson, 2006a \& 2006b] as well as focuses on the creation and assurance of the OER collaborativeness. The Social Web promotes valuable autonomous, collaborative and conversational environments for the educational area.

\subsubsection{Open Linked Data}

Tim Berners-Lee — creator of the WWW - presented a group of good practices for the publication and connection of structured data on the Web: the beginning of Linked Data [Berners-Lee, 2006]. This implies the Web's evolution towards a global space for information [Heath, 2011] navigated through linked, structured data in place of Web documents, as is now the case.

For OER initiatives, these practices lead to the transition from a HTML-based Web to a Linked Data Web. The information published in the HTML-based Web targets the human user, whereas the Linked Data Web is expressed in Resource Description Framework (RDF)language [W3C, 2009a], where software agents can automatically exploit (compile, add, interpret, publish, mix, etc.) data enhanced by vocabularies and ontologies that use the explicit and formal specifications of a shared conceptualization [Gruber, 1993]. 


\subsubsection{Social Network Analysis}

Social Network Analysis (SNA) is a sociological approach that empirically analyses structural patterns; that is, patterns resulting from social relations among network members [Scott, 91]. It aims to monitor social relationships between individuals, groups, communities, units, organizations, etc.

Firstly, SNA has the power to reduce a system to its individual components and their relationships (network characterization), as well as the existence of several (sociometric) metrics and indicators that characterize these structures [Wasserman and Faust, 94]. Secondly, SNA is an approach that has gained popularity in recent years. It has been applied to problem solving in various scientific disciplines and social engineering, e.g., [Mueller-Prothmann, 2004] discusses the use of SNA as a method for identifying experts and sustainable knowledge transfer. Also, [Pham, 2011] proposes the use of social information users to generate recommendations based on academic collaboration information and recommendations based on trust.[Han, 2008] applies social network analysis to a repository of educational resources, looking for ways to improve access. Thirdly, we used SNA to develop solutions that support the identification, visualization and analysis of networks occurring in the OCW/OER knowledge domain. Finally, this strategic knowledge between different actors can create OCW opportunities to improve the processes of OCW/OER creation, use, reuse and adaptation, community identification and support, that is, they promote open content, as well transfer explicit and conserve implicit knowledge.

\section{Research Project Description}

The project presented in this paper was called "Strategies for development and research of open educational resources". It was funded by the UPM Relations with Latin America Programme (AL09-PID-36) and was led by the UPM OCW Office within the Ibero-American Universities Consortium (Universia.net).

The project also received strong backing from UTPL and UPM, respectively. Furthermore, both institutions share common strategic goals like the promotion of educational contents for reuse, sharing and open access, etc.

\subsection{Scope and main goals and methodology}

One primary objective of this project was for UTPL to join the OCW community. As a result, the project also targeted the establishment of an OCW Office for UTPL with the support of a new OCW site called http://ocw.utpl.edu.ec. This valuable outcome was possible thanks to UPM-OCW's leadership and experience enabling technologies, i.e., with the following tasks:

- $\quad$ Implementation of a new OER Content Service for UTPL

- $\quad$ Publication of a set of lectures under OCW agreement, i.e., mainly with open access.

Another primary objective of this project was to study different research lines of strategic interest for OER for vertical and lecturer-focused production cycles [CERI, 
2007], educational material quality, how to measure collaborativeness, creativity and competence learning in open production models, and problems of sharing and remixing or locating and accessing educational material. Thanks to initiatives like OCW and movements that promote the openness of knowledge, like Open Access, educational material is being generated in different branches of knowledge and made available to the world. One of the problems associated with this growth is that it is hard to find material that meets specific information needs. The research team chose emerging technologies, such as Social Web and Semantic Web technologies, to tackle the outlined situations, and defined strategies and implemented mechanisms to rise to these OER challenges. In particular, the project dealt with the research lines:

a) Study of quality models for OER improvement. OCW initiatives are growing around the world. It is necessary to build a model to verify the quality of the processes used to produce OCWs, the quality of OCW as a finished product and the technical characteristics of OCW use and adaptation.

The goal is to develop a model to ensure the quality of OCW course content. OER production. According to the role played by education in the knowledge society, lecturers are no longer teachers and dispensers of knowledge but facilitators/mentors of open educational practices. This switch is crucial for promoting innovation and change in educational practices [OLCOS, 2007], i.e., to improve the acquisition of skills and to ensure successful participation in a knowledge-based society (autonomy and creativity, critical thinking and problem-solving skills, work collaborative teamwork and communication and social skills).

The goal is to develop the OER production cycle according to the Social Web philosophy that enhances resource sharing and enrichment.

c) OER meta-analysis (application of Social Network Analysis): Social network analysis is a type of analysis for gathering relevant information to complement other analyses, such as statistics, metrics and indicators. SNA highlights the different features of a social network: hidden information and behaviour patterns.

The goal is to characterize and describe events held as part of the TAEE(Technologies Applied to E-Learning)project, according to a series of questions related to proposals by the organizers of the events programme .

Promotion of interoperability and reusability to retrieve in formation about educational material using Semantic Web research.

Access to educational resources through traditional Web mechanisms is an obstacle to the localization of useful information and reduces the chances of sharing and exchanging resources. This heterogeneity of formats, schemas and languages used to publish educational material is a barrier to the performance of tasks such as OER discovery, exchange and reuse. If these resources were described using a common vocabulary and standard language, any human or software-based agent could understand and process their contents.

The goal is to explore the use of the semantic paradigm in the context of open e-learning. Particularly, we build an ontology in order to describe OERs and their conditions of use (using a Creative Commons Licence). Student and 
teacher portals can support the educational material referral, discovery, reuse or remix process from a variety of repositories.

Evaluation of skills associated with the use of OER. Social Web tools and concepts can improve the acquisition of collaborative skills and creativity.

The goal is to establish a model of rubrics to support collaborative skills development and creativity in the use of Web 2.0 tools.

\subsection{Approach, main outcomes and validation}

According to the research lines discussed in Section 3.1, the main outcomes of this project targeted OER focused particularly on the OCW area. Their details and importance are outlined in the following sections.

\subsubsection{Quality models research line}

In this project, we studied quality models for OCW. We considered a quality model for educational contents access based mainly on the following categories (also identified as areas). The model highlights eight major areas, taking a social constructivist approach considering the key elements for generating quality content. The identified areas are: Development and distribution models; Academic scope; Content development and user interfaces; Evaluation of education-oriented support content; Human-computer interaction communication tools; Evaluation of interoperability-oriented technical requirements; Evaluation of repository use and accessibility

Validation:

We then proposed a life cycle for evaluating educational contents quality. The result was applied to OCW Universiain 2009. OCW Universia has more than 40 member universities. The process was as follows: (i) the model was evaluated by Universia; (ii) the Universia editorial board added some key indicators that they used to select the best educational contents, and (iii) we developed an opinion poll that was sent to Spanish universities. As a result of this study, we built a quality model associated with OER development.

This outcome was analysed at OCW UPM and found to be satisfactory. The results were also presented at the Universia Meeting (May 2009) and the International Campus Conference (Loja, May 2009) [Tovar, 2009], [Piedra, 2010d], [Romero, 2011].

\subsubsection{OER production research line}

Social software and Web 2.0 provide a new window of opportunity for implementing open educational practices and resources and developing the skills needed in the knowledge society.

Until now, OER development has been mainly studied from the pedagogical point of view. In this context, we proposed a new OER production cycle. This process mainly included the key role of social components and Semantic Web. 
From a social dimension, we think that open access would improve human knowledge .We formulated the hypothesis that knowledge is a public commodity and technology - especially Web 2.0 - offers a valuable opportunity for getting core skills into our knowledge society [Piedra2009a].

As a result, we say that collective thinking, social tools (Web 2.0) and the Semantic Web would be of interest for educational material repositories. Moreover, the integration of social tools is useful for OERs, as they promote the active participation of creators and users [Piedra, 2010a]. Web search engines linked to educational platforms and social tools locate OERs. Also, OERs include metadata and tags to promote open and collaborative access by identifying social authorship through appropriate intellectual property licences. We proposed a model that presented continuous feedback to ensure resource flexibility and continuous improvement across all phases, e.g., analysis, evaluation, etc. In addition, our model conforms to fundamental OER principles, that is, it takes an educational point of view for developing end-user knowledge and skills. Also, it was published with open access, i.e., using Creative Commons licences.

As other outcomes of this work, we presented these successful results at the EATIS 2009 Conference [Piedra, 2009a]. Thus, we presented these other successful results at the IEEE ICALT 2009 Conference [Piedra, 2009b];

Validation:

This research line promoted the development of an OER environment and practices. The educational content production cycle developed conforms to a co-author model. This means that educational content is created, shared, re-used, enhanced and enriched from a collaborative perspective rather than according to the classical model of content development. The traditional learning object model — create, assemble, package and release - takes a one-too-many approach, where users are passive consumers. Collaboratively creating, sharing, using, re-using, improving and enriching OERs has proved to bean alternative that should be promoted by higher education institutions to help students and teachers to acquire useful competences and skills for successful participation in the knowledge society.

\subsubsection{Meta-analysis research line}

We used meta-analysis techniques to study the potential of social networks for OER and OCW ecosystems. We think that meta-analysis offers remarkable information for jobs with collaborative work factors.

Consequently, we selected Web 2.0 strategies that UTPL used for OER development. We applied the same concept for semantic annotation strategies in collaborative and social environments. At this point, we would like to point out that these strategies have been applied before but there is no consolidated research on social networks yet. To do this, we selected our proposed social authoring environment. Researchers from UPM and UTPL studied this OER creation, evolution and quality control solution.

We think that meta-analysis would be another tool of interest. It could gather information that would guide and improve the social authoring environment. As a 
result, we proposed social network meta-analysis to further evolve Semantic Web research in conjunction with the OER area.

As another outcome of this study, we presented these results at TAEE 2010 [López, 2010]) and IEEE EDUCON 2010 Conference: "Meta-analysis of the TAEE project applying social network analysis” [Piedra, 2010b].

Validation:

TAEE congresses have developed positively as reflected by the diversity of subjects addressed and their adaptation to new techniques and products in the e-learning world. However, there is room for improvement as regards the relations among organizations and actors from different organizations in order to strike a better balance between organizations on different continents.

The answers to the proposed questions in this study were based on statistical data and results obtained using social network analysis techniques. By analysing the relationships between families and thematic keywords, we find that social network analysis rounds out statistical analysis because it provides a different approach that simply, quickly and graphically discloses hidden information.

\subsubsection{Semantic tagging and search architecture research line}

As discussed earlier, OERs can be accessed through the Web, which has evolved continually towards the development of social software. However, there are other obstacles, i.e., there is no guarantee of full content sharing and exchange. To facilitate educational resource sharing and exchange, it is essential to use semantic technologies and thus ensure the interoperability of these resources at different levels: institutional, technological, and inter-machine interoperability. Shared vocabularies, and ontologies are now the mechanisms used to describe and represent Web concepts and objects. However, ontology implementation can be complex and may require the intervention of more than one user type. Ontologies have a social dimension [Kotis, 2010] and should be developed, evaluated, discussed by communities and evolve within domainspecific information spaces.

In this framework, we think that semantic technologies and metadata schemas would be a complementary tool for OER description. In particular, we propose the construction of an ontology based on conceptual maps. The OER-CC ontology was implemented with the aim of describing OERs and their conditions of use (Creative Commons licensing). Thus, this proposed solution enables any human or softwarebased agent to process and understand the contents, i.e., they could perform tasks autonomously.

To achieve this goal, we developed our own ontology (see Figure 3) that we named OER-CC. In particular, OER-CC was used to describe OERs using Creative Commons licences. The main properties of OER-CC are: (i) extract metadata from OER repositories and tags entered by users, (ii) rank results by order of OER importance, (iii) deploy implemented ontology using concept mapping techniques, among others.

We presented the outcomes of this study at [Piedra, 2010a] and [Piedra, 2010c]. Validation:

Two types of validation were conducted: 
1) The ontology is developed from concept maps (using CmapTools-COE) and using Protégé. Ontologies were evaluated independently during the development of each version, i.e., Syntactic evaluation using Pellet and RacerPro 1.5.2 and 2.0 reasoners, and taxonomy evaluation to verify that hierarchies are defined correctly.

2) Development of questions, whose answers were obtained via SPARQL. This shows that the ontology is complete in its domain. We also defined queries to retrieve metadata focused on educational materials described by the proposed ontology. This shows that it is feasible to use the retrieval model to improve OER accessibility and remixing.

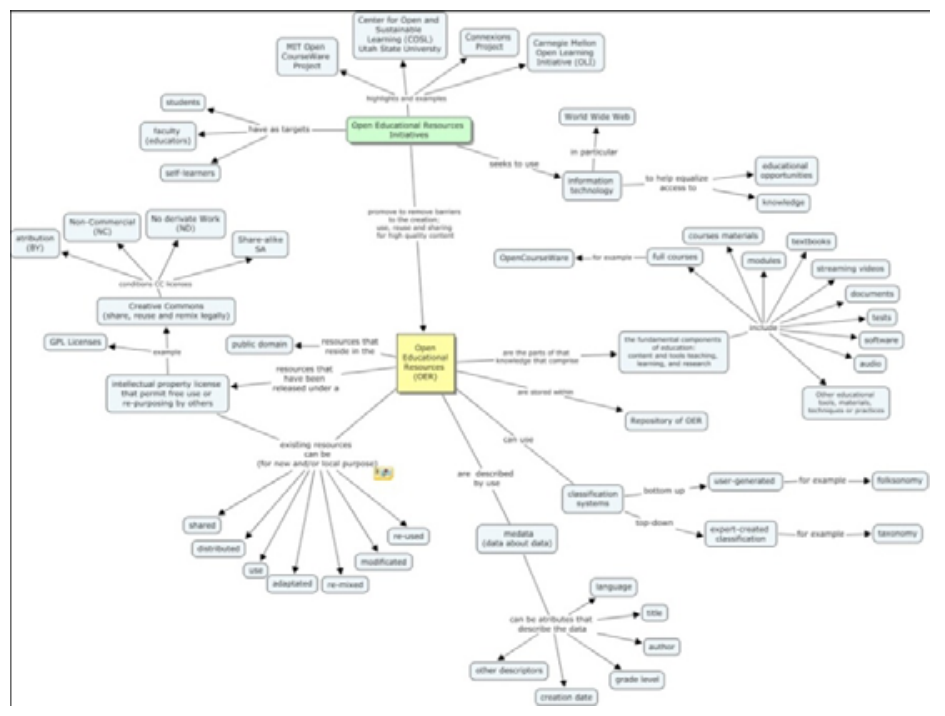

Figure 3: Concept Map: Open Educational Resources Knowledge Domain

The proposal was implemented in the context of project management software development in an academic setting. The prototype search for software requirements documents generated by a development project demonstrated that it is possible to use the structure defined by the ontology to organize and integrate the metadata of resources stored in databases or existing files.

The main contribution was that it implemented and validated the OER-CC ontology modelling the OER domain and Creative Commons open content licensing. Once implemented, the ontology was instantiated with some educational resources generated by a higher education institution and inference tests were run using ratios obtained by classifying the result of educational resources according to the defined model. Also there was an improved resource search architecture, which attempts to integrate the best of social (collective intelligence) and semantic (data integration and structuring) worlds.

\subsubsection{Competence assessment}


Throughout the curriculum, it is essential to implement a teaching-learning process assessment system to determine the level of learning objective achievement for each course or subject.

The adoption of user-centric tools and technologies is encouraging as a specific example of a competence-based education system, where students are the centre of the training process.

As mentioned in previous sections, there is evidence that Web 2.0 tools and Social Web services could have a valuable impact on improving education. Moreover, Web 2.0 tools are able to publish and share ideas, experiences, opinions and links. Consequently, Web 2.0 opens up a wealth of opportunities for social software, i.e., it could be of interest for essential skill and competence development in today's knowledge era.

In this student collaborative learning assessment scenario, rubrics have been used to measure the level of skill acquisition in a Web 2.0 tools management course.

The rubrics enhance knowledge and understanding rather than memorization, deep learning and student-centred learning rather than superficial and passive learning [Pausch, 1997].

As part of the proposal, three rubrics based on the learning taxonomy [Bloom, 1956] and [Church, 2008] —-knowledge, comprehension, application, analysis, synthesis and evaluation-, were used in an attempt to assess student co-curricular Social Web activities [Tovar, 2009].

They are: (i) items assessing Wiki editing, (ii) items assessing blog headings and (iii) items assessing social bookmarking headings (see Table 1 for a partial example of a wiki editing rubric developed in this project).

We presented the outcomes of this study in "Measuring Creativity as a Competence Developed by Open Resources" [Tovar, 2009], "Measuring collaboration and creativity skills through rubrics, Experience from UTPL Collaborative Social Networks Course” [Piedra, 2010d] and "Quality model proposal for educational material production in OCW sites," [Romero, 2011].

Validation:

To evaluate whether rubrics were easy to use and explain [Andrade, 2000], we conducted a validation through statistical indicators calculated on academic performance before and after rubrics. The rubrics provide students with more informative feedback about their strengths and what they need to improve. Rubrics reduce the time it takes teachers to assess student work. Rubrics help to develop and acquire skills and clarify and consolidate ideas and expectations. 


\begin{tabular}{|c|c|c|c|c|}
\hline \multirow{2}{*}{$\begin{array}{l}\text { Dimension } \\
\text { (rubric } \\
\text { criteria) }\end{array}$} & \multicolumn{4}{|c|}{ Proficiency levels } \\
\hline & Poor & Satisfactory & Good & Very good \\
\hline $\begin{array}{l}\text { Intellectual } \\
\text { engagement } \\
\text { with key } \\
\text { concepts }\end{array}$ & $\begin{array}{l}\text { Wiki pages } \\
\text { make no } \\
\text { reference to } \\
\text { issues and } \\
\text { key concepts } \\
\text { raised } \\
\text { inreadings } \\
\text { and/or } \\
\text { module } \\
\text { activities }\end{array}$ & $\begin{array}{l}\text { Wiki pages } \\
\text { make some } \\
\text { reference to } \\
\text { issues and key } \\
\text { concepts } \\
\text { raised } \\
\text { inreadings } \\
\text { and/or module } \\
\text { activities }\end{array}$ & $\begin{array}{l}\text { Wiki pages } \\
\text { demonstrate } \\
\text { awareness of } \\
\text { most key } \\
\text { concepts } \\
\text { raised } \\
\text { inreadings } \\
\text { and/or module } \\
\text { activities. }\end{array}$ & $\begin{array}{l}\text { Wiki pages } \\
\text { demonstrate } \\
\text { engagement } \\
\text { with the key } \\
\text { concepts raised } \\
\text { inreadings } \\
\text { and/or module } \\
\text { activities. }\end{array}$ \\
\hline $\begin{array}{l}\text { Structure, } \\
\text { spelling and } \\
\text { grammatical } \\
\text { errors }\end{array}$ & $\begin{array}{l}\text { Wiki pages } \\
\text { have poor } \\
\text { spelling and } \\
\text { grammatical } \\
\text { mistakes }\end{array}$ & $\begin{array}{l}\text { Wiki pages } \\
\text { have some } \\
\text { spelling and } \\
\text { grammatical } \\
\text { mistakes. Text } \\
\text { entered with } \\
\text { limited } \\
\text { enhancements } \\
\text { - }\end{array}$ & $\begin{array}{l}\text { Wiki pages } \\
\text { have few } \\
\text { spelling and } \\
\text { grammatical } \\
\text { mistakes. Text } \\
\text { is enhanced. }\end{array}$ & $\begin{array}{l}\text { Spelling and } \\
\text { grammatical } \\
\text { mistakes are } \\
\text { rare. The wiki } \\
\text { pages are } \\
\text { structured, } \\
\text { formatted and } \\
\text { enhanced to } \\
\text { increase } \\
\text { readability. }\end{array}$ \\
\hline$\cdots$ & $\cdots$ & $\cdots$ & $\cdots$ & $\cdots$ \\
\hline
\end{tabular}

Table 1: Rubrics for wiki editing

\subsubsection{Searching for educational material. Other outcomes}

To conclude this section of outcomes, note that other objectives were related to UTPL adhesion to OCW Universia. As mentioned earlier, UTPL was required to conform to the following requirements for membership of this worldwide consortium: (i) set up a new OCW web site (see Figure 4), (ii) promote content re-usability, sharing and distribution, and (iii) publish a minimum set of ten lectures under a Creative Commons license agreement, i.e., mainly with open access.

As a result, some computing-related lectures were published on the UTPL OCW web site. Almost $90 \%$ of UTPL distance courses have now been published under Creative Common licenses and are being integrated in the UTPL OpenCourseWare repository. Note that these courses needed to conform to some quality metrics, like contents organization, course information, program of contents and learning guide, etc. In addition, they offer access to particular contents created by lecturers and 
students using social tools (http://www.slideshare.net/eccutpl, www.youtube.com/ eccutpl, www.utpl.edu.ec/ecc/wiki, www.utpl.edu.ec/eccblog). Also, users of this OCW-UTPL initiative completed different tasks using semantic web technologies (mainly metadata), e.g., educational resource creation, classification or even semantic annotation. The same users used education-related tags from their own UTPL competence-based model.

To conclude this section, we give other interesting details related to OCW-UTPL structure. OCW-UTPL used the Educommons platform (http://plone.org/products/ educommons). EduCommons is designed for the creation of OCW projects. EduCommons is a content management system, not a learning management system, because it does not include an assessment process and support for interactive tasks (blogs, chat, wikis, etc.). It is an administration system configured mainly using Python, Zope and Plone technologies. Also, it is distributed under a GNU General Public License. Thus, this assessment ensured excellent work flow management, i.e., dissemination of educational contents.

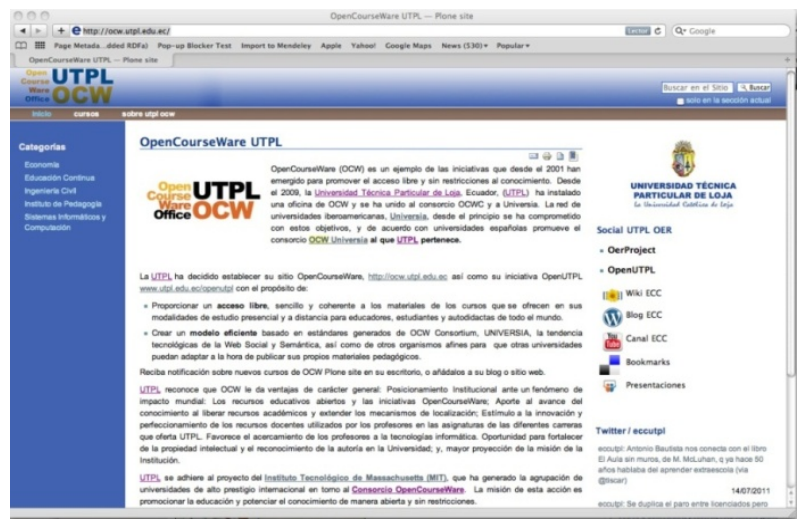

Figure 4: UTPL OpenCourseWare Web site

\section{Conclusions}

The project served to consolidate a newly created research group with members from several institutions that have different maturity profiles. The presented outcomes were the result of early research by junior researchers attached to the UTPL whose dissertations were supervised by senior researchers from the UPM. The results have led to the emergence of new opportunities to integrate into new networks with other prestigious research groups in the e-learning area.

Some criteria have been identified to show the impact of the project outcomes. These criteria refer to the consolidation of GICAC as a research group in the field of technologies applied to education, the maturity of its junior research members, and the networking leading to participation in other projects in the future. See Table 2 below for the impact of the results according to the criteria indicators. 


\begin{tabular}{|c|c|c|}
\hline Criteria & Indicators & Data \\
\hline $\begin{array}{l}\text { Consolidation } \\
\text { of GICAC }\end{array}$ & \begin{tabular}{|l} 
Number of published \\
international papers (peer review) \\
while the project was active and \\
directly related to its outcomes
\end{tabular} & $\begin{array}{l}\text { - } 9 \text { in } 2010 \\
\text { - } 4 \text { in } 2009\end{array}$ \\
\hline & $\begin{array}{l}\text { Number of projects funded by } \\
\text { public institutions since } 2009\end{array}$ & $\begin{array}{l}\text { - } 3 \text { active projects: e- } \\
\text { Madridproject, (2010-2014). } \\
\text { Madrid Regional Government } \\
\text { eMadrid S2009/TIC-1650, N- } \\
\text { AL11-P(I+D)-17 (UPM), LUD } \\
\text { Linked Universities Data, } \\
\text { UTPL } \\
\text { - } 3 \text { in } 2009 \text { \& 2010: AL09PID36 } \\
\text { (UPM) project; Secretaria } \\
\text { Nacional de Ciencia y } \\
\text { Tecnologia of Ecuador } \\
\text { (SENACYT, Ecuador)), Red } \\
\text { OBER -Objetos } \\
\text { (SpanishNationalResearchPlan } \\
\text {, Spain) }\end{array}$ \\
\hline \multirow{2}{*}{$\begin{array}{l}\text { Maturity of } \\
\text { junior research } \\
\text { members } \\
\end{array}$} & $\begin{array}{l}\text { Number of PhD students in } \\
\text { GICAC }\end{array}$ & $\cdot 11$ \\
\hline & $\begin{array}{l}\text { Number of "Advanced Studies } \\
\text { Certificates" earned during the } \\
\text { project in GICAC (this certificate } \\
\text { is a pre-doctoral qualification in } \\
\text { the Spanish education system). }\end{array}$ & $\begin{array}{l}\text { - } 3 \text { in } 2009 \\
\text { - } 8 \text { in } 2010\end{array}$ \\
\hline Networking & $\begin{array}{l}\text { Number of OER research project } \\
\text { proposals submitted (2011) }\end{array}$ & $\begin{array}{l}\text { - } 3 \text { (American, European and } \\
\text { Spanish) }\end{array}$ \\
\hline
\end{tabular}

\section{Table 2: Results for project impact}

The group is now pursuing research in the following areas. Firstly, GICAC is continuing its work on the emerging area of the linked data (Linked Data). The Linked Data Project is an initiative that invites individuals and organizations alike to provide open access their data and connect with others (using some good practices). The aim is for data to be used in as yet unimaginable ways. Linked Data is an initiative that emulates the traditional Web philosophy that I can write whatever I want on my page and create links to other related pages, but, in this case, using raw data, which are both human and machine readable. GICAC is now working on two projects funded by UPM and UTPL focused on this hot topic. The major goals are to develop and deploya Social-Semantic and Data Web-based infrastructure that integrates heterogeneous data from open contents. Currently, it describes and links data from its OER and OCW repositories using agreed vocabularies and Linked Data principles, respectively. Also, GICAC is experimenting with the interoperability of OCW data from Spanish universities data through the OCW Universia consortium. 
Secondly, GICAC has been a member of the eMadrid Programme since 2010. eMadrid is the e-learning excellence network funded by the Regional Government of Madrid. Its members are the Universidad Carlos III de Madrid (UC3M), who acts as a coordinator, Universidad Autónoma de Madrid (UAM), Universidad Complutense de Madrid (UCM), Universidad Politécnica de Madrid (UPM), Universidad Rey Juan Carlos (URJC) and Universidad Nacional de Educación a Distancia (UNED), together with a large number of associated companies and educational institutions. The aim of the network is to provide leadership and perform advanced research in the area of elearning, including technology transfer to companies.

The eMadrid network addresses many topics related to the application of open source principles in the educational context and in opening up alternatives to the learner. GICAC UPM focuses on OER. The open source principles have been taken from content authoring software development and OER there is now a very strong OER movement that is exponentially increasing the amount of freely available educational material. With a steady increase in the number of OERs available worldwide, the question now arises of how to viably discover and retrieve these resources. Recent advances in web technology, such as the Social Web and Linked Data technologies can help here.

Thirdly, GICAC has participated, with other prestigious groups, in the preparation of several proposals (still pending approval) in the field of nextgeneration OERs for remote experiments as part of Spanish and American (NSF) research programmes.

GICAC is to contribute a semantic and social strategy to improve more interoperable, discoverable and re-usable collaborative OER creation and quality assurance, as well as the development of a learning environment.

\section{Acknowledgements}

This work has been supported by projects AL09-PID-36 "Strategies for development and Research of Open Educational Resources" and AL07-PID-054 "A technological framework applied to engineering academic and research networks", funded by the UPM Relations with Latin America Programme. It has also been partially supported by the Republic of Ecuador's National Secretariat of Science and Technology (SENESCYT). Finally, we would like to thank Madrid Regional Government for its support through the EMadrid Network of Excellence S2009 TIC-1650.

\section{References}

[Andrade, 2000] Andrade, H.: Using rubrics to promote thinking and learning. Educational Leadership, 2000.

[Berners-Lee, 2001] Berners-Lee, T.; Hendler, J.; Lassila, O.: The Semantic Web, in Scientific American, 34-43, Vol. 284, Iss. 5, May 2001.

[Berners-Lee, 2006] Berners-Lee, T.: Linked Data, 2006, on http://www.w3.org/DesignIssues/LinkedData.html.

[Bloom, 1956] Bloom, B.: Taxonomy of Educational Objective, Hand-book I: The Cognitive Domain. New York: David McKay Co., Inc., 1956. 
[Casserly, 2007] Casserly, C.;“The economics of Open Educational Resources”, in Educational Technology Magazine, 14-19, Vol. 47, Number: 6, 2007.

[Chicaiza, 2010] Chicaiza, J.; López, J.; Piedra, N.; Martínez, O.; Tovar, E.: Usage of social and semantic web technologies to design a searching architecture for software requirement artefacts, IET Software Journal, 407 - 417, Vol. 4, December 2010.

[Churches, 2008] Churches A.: Welcome to the $21^{\text {st }}$ Century http://edorigami. wikispaces.com/21st+Century+Learners, 2008

[Cueva, 2011] Cueva Carrion, S.; Rodriguez Morales, G.; Tovar Caro, E.; "Implementation of social and semantic tools into open educational resources production," Global Engineering Education Conference (EDUCON), 2011 IEEE, pp.712-720, 4-6 April 2011

[Downes, 2007] Downes, S.; “Models for Sustainable Open Educational Re-sources”, in Interdisciplinary Journal of Knowledge and Learning Objects, Vol.: 3, 2007.

[Fitzgerald, 2007] Fitzgerald, B.: Open Content Licencing (OCL) for Open Educational Resources, in Proceedings OECD Expert Meeting on Open Educational Resources, Malmo, Sweden, 2007.

[Gruber, 1993] Gruber T., “Toward principles for the design of ontologies used for knowledge sharing”. Knowledge Systems Laboratory, Stanford University, KSL 93-04, 1993. (Tech. Rep)

[Han, 2008] Han P., et al, "Exposure and Support of Latent Social Networks among Learning Object Repository Users”, Journal of Universal Computer Science, vol 14 (10), pp. 1717-1738

[Heath, 2011] Heath, T.;Bizer, C.: Linked Data: Evolving the Web into a Global Data Space, Morgan I\& Claypool, 2011.

[López, 2010] López ,J.A.;Piedra, N., Tovar, et al.,Meta-analysis of the TAEE project applying social network analysis. Education Engineering (IEEE EDUCON), Madrid, Spain, April 2010

[Mueller-Prothmann, 2004] Mueller-Prothmann, T., Finke, I.: SELaKT - Social Network Analysis as a Method for Expert Localisation and Sustainable Knowledge Transfer. JUCS(2004) 691-701

[O’Reilly, 2005] O’Reilly T. What is web 2.0? design patterns and business models for the next generation of software. (Tech. Rep.). 2005. O’Reilly Network.

[OECD, 2007] OECD, "Giving Knowledge for Free. The Emergence of Open Educational Resources, Centre for Educational Research and Innovation (CERI), 2007.

[OLCOS, 2007] Open educational practices and resources. OLCOS Roadmap 2012 (EduMedia Group, Ed.) (No. ISBN 3-902448-08-3). Open eLearning Content Observatory Services.

[Pausch, 1997] Pausch, L.; Popp, M.: Assessment of information literacy: Lessons from the higher education assessment movement. Paper presented at the meeting of the Association of College and Research Libraries, Nashville, TN, 1997

[Pham, 2011] Pham, M.C., et al, A Clustering Approach for Collaborative Filtering Recommendation Using Social Network Analysis. J. UCS(2011) 583-604

[Piedra, 2009a] Piedra, N., Chicaiza, J., López, J., Martinez, O. \& Tovar, E. Open Educational Practices and Resources Based on Social Sotfware, UTPL experience. ACM. In Proceedings of the 2009 Euro American Conference on Telematics and information Systems: New Opportunities To increase Digital Citzenship, Prague, Czech Republic, June 03 - 05, 2009. EATIS '09. 
[Piedra, 2009b] Piedra, N., Chicaiza, J., López, J., Martinez, O. \& Tovar, E. Open Educational Practices and Resources Based on Social Software: UTPL experience. IEEE Computer Society. (The 9th IEEE International Conference on Advanced Learning Technologies). Riga, Latvia, July 2009.

[Piedra, 2010a] Piedra, N.; Chicaiza, J.; López, J.; Martínez, O.; Caro, E.T.: An approach for description of Open Educational Resources based on semantic technologies, in proc. of 1st IEEE Global Engineering Education Conference (EDUCON), 1111 - 1119, Madrid, April 2010

[Piedra, 2010b] Piedra, N.; Chicaiza, J.; López, J.; Caro, E.T.: Meta-analysis of the TAEE project applying social network analysis, in proc. of 1st IEEE Global Engineering Education Conference (EDUCON), 129 - 136, Madrid, April 2010

[Piedra, 2010c] Piedra, N.; Chicaiza, J.; López, J.; Tovar, E.; Martínez, O.: Design Study of OER-CC Ontology - A Semantic Web Approach to Describe Open Educational Resources, $10^{\text {th }}$ IEEE Int Conf on Advanced Learning Technologies (ICALT), 207 - 209, Sousse, July 2010

[Piedra, 2010d] Piedra, N. Chicaiza, J. Romero, A. López, J. \& Tovar, E. Measuring collaboration and creativity skills through rubrics: Experience from UTPL collaborative social networks course. Education Engineering (IEEE EDUCON), Madrid, Spain, April 2010

[Piedra, 2011] Piedra, N.; Chicaiza, J.; Lopez, J.; Tovar, E.; Martinez, O.: Finding OERs with Social-Semantic search, in proc. of in proc. of IEEE Global Engineering Education Conference (IEEE EDUCON), 1195 - 1200, Amman, April 2011.

[Piedra, 2010e] Piedra, N., Chicaiza, J., López ,J., Martinez, O., Tovar, M. Design study of OER-CC ontology. A semantic web approach to describe Open Educational Resources, 10th IEEE IntConf on Advanced Learning Technologies (ICALT), July 5-7, 2010, Sousse, Tunisia.

[Romero, 2011] Romero, A.; Piedra, N.; Tovar, E.; "Quality model proposal for educational material production in OCW sites," Global Engineering Education Conf (EDUCON), 2011, vol., no., pp.1074-1080, Amman - Jordan, 4-6 April 2011

[Richardson, 2006a] Richardson W. Blogs, wikis, podcasts and other powerful web tools for classrooms, Corwin Press, 2006.

[Richardson, 2006b] Richardson W. The new face of learning, Edutopia. 2006.

[Scott, 91] Scott, J.: “Social Network Analysis. A Handbook”, Sage, London et al. (1991).

[Tovar, 2008] Tovar, E., Piedra, N., Chicaiza, J. \& Carrillo, J. A Technological Framework Applied to Engineering Academic And Research Networks. INTERTECH, X Int Conf on Engineering and Technology Education, Santos, Brazil, 2008

[Tovar, 2009] Tovar, E.; Piedra, N.; Chicaiza, J.; Lopez, J.: Measuring Creativity as a Competence Developed by Open Resources, in proc. of OpenCourseWare Consortium (OCWC Global 2009): Content, Creativity, Infrastructure, Monterrey - Mexico, April, 2009

[Tovar, 2011] Tovar, E.; Piedra, N.; Chicaiza, J.; Lopez, J.; O. Martinez: Exploring the advantages of using linked data with OERs, in proc. of OpenCourseWare Consortium (OCWC Global 2011), Cambridge, Massachusetts, USA, May, 2011

[W3C, 2009a]. W3C. Resource Description Framework (RDF). W3C, Semantic Web - RDF Working Group, ,http://www.w3.org/RDF/

[W3C, 2009b]. W3C. SPARQL Query Language for RDF. W3C. Retrieved Dec, 2009, http://www.w3.org/TR/rdf-sparql-query/ 
[Wasserman and Faust, 94] Wasserman, S., Faust, K., 1994: "Social Network Analysis: Methods and Applications”, Cambridge University Press, Cambridge/MA (1994).

[Wiley, D. A., 2003]. A modest history of OpenCourseWare. Autounfocus blog,. http://www.reusability.org/blogs/david/archives/000044.html

[Ziliotto, 2008] Ziliotto, C.; Mocellin, E.; Trzeciak, D. and Freitas, M. Open access to digital scientific information: difficulties and tendencies, Transinformacao Journal, 309-318, Vol. 20, Iss. 3, 2008. 